\title{
A Rare Case of Congenital Syphilis and a Supernumerary Fourth Molar in an Early 20th Century African American Woman
}

\author{
Stella Ioannou ${ }^{a *}$ and Maciej Henneberg ${ }^{b}$ \\ ${ }^{a}$ Biological Anthropology and Comparative Anatomy Research Unit, The University of \\ Adelaide, Adelaide, South Australia, 5005 \\ ${ }^{\mathrm{b}}$ Institute of Evolutionary Medicine, University of Zurich, Zurich, Switzerland, 8006
}

Keywords: disease; mercury; mandibular distomolar; morphology; supplemental teeth

ABSTRACT Congenital syphilis is a disease recognized for interfering with odontogenesis, producing specific dental characteristics including Hutchinson's incisor, Moon's molar, Fournier's molar and mulberry molar, while its past treatments including mercury are known to affect amelogenesis. Supernumerary teeth, mainly associated with syndromes, are not commonly found in cases of congenital syphilis. A rare case of congenital syphilis in an individual (P000707) treated with mercury and a mandibular left fourth molar with normal morphology is presented.

Materials and Methods: During a systematic examination of 28 skeletons with treponemal disease at the Smithsonian museum in Washington, DC, a supernumerary mandibular distomolar in one individual (P000707) was revealed.

Results: P000707 was an African American female, 26 years of age. Dentition showed severe enamel hypoplasia of the maxillary and mandibular incisors, left canine, and upper first molars, consistent with the effects of treatment of congenital syphilis by mercurial compounds. Crown of the left mandibular distomolar has typical molar morphology but is smaller in size than other permanent molars. Arrangement of grooves resembles the +4 pattern, but is complex due to crenulation. Oblique x-ray revealed that the fourth molar had one root with a pulp chamber extending towards the apex, suggesting taurodontism. No other distomolar teeth were present.

Conclusions: Congenital syphilis and treatment containing mercury may not influence the development of supernumerary teeth due to: (1) the age at which the development of the fourth molar takes place, (2) the stage of the infection at the time of development and (3) the age at which treatments containing mercury are administered to patients with congenital syphilis.

Congenital syphilis is a disease caused by the transmission of Treponema pallidum, from the mother to the fetus during pregnancy or at birth. In the neonate, various systems are affected. Pathological signs appear in two stages of the disease. During the early stage, skeletal manifestations include periosteal reactions, osteochondritis, and osteomyelitis (Hira et al., 1985; McLean, 1931) while during the late stage, signs can include frontal bossing, short maxilla, high palatal arch, saddle nose, Higoumenakis's sign, diaphysitis, metaphysitis and sabre shins (Fiumara and Lessell, 1970; Rasool and Giovender, 1989). However, the disease is most recognized for interfering with tooth formation (odontogenesis), producing certain characteristic teeth including Hutchinson's incisors, Moon's molar, Fournier's molar and the mulberry molar (Fournier, 1886; Hutchinson, 1863; Karnosh, 1926; Moon, 1884). Even though these characteristic dental signs in congenital syphilis are seen in the permanent teeth (upper central incisors and first molars), which erupt approximately at
6-8 years of age, the dental abnormalities in these teeth are produced during the early stages of the disease, that is, once the infection and fever set in around the time of birth affecting initial crown formation. However, these dental abnormalities do not occur in all cases of congenital syphilis. The incidence of Hutchinson's incisors ranges from 30 to 50\% (Putkonen and Paatero, 1961), while changes in first permanent molars range between 3 and $37 \%$ (Berfield, 1971).

In the past, mercury was used to treat congenital syphilis due to its antibacterial effects (Hutchinson, 1874, 1878; Warner, 1881). Even though mercury was seen to benefit infected individuals, it was also seen to produce dental abnormalities that were different from

${ }^{*}$ Correspondence to:

Stella Ioannou

The University of Adelaide, School of Medicine

Adelaide 5005, South Australia, Australia

email: stelzy_25@hotmail.com 
those caused by the disease. Hutchinson recognized that mercury affected amelogenesis resulting in severe enamel hypoplasia (Hutchinson, 1878). Treatments containing mercury were given to infants soon after birth, the time which enamel formation in permanent teeth begins. First permanent molars and incisors begin their formation around birth and this is when they are exposed to disease. Mercury used to treat syphilitic infants continued for months after birth, severely affecting other tooth formation, depending on the length of time the treatment was administered (Hutchinson, 1878). The abnormalities produced by congenital syphilis can be combined with the effects of treatment containing mercury (severe hypoplastic effects) (Hutchinson, 1878; Moon, 1884). Treatment with mercury was commonly used in cases of congenital syphilis until the early 20th century. The whole suite of changes caused by congenital syphilis and treatments containing mercury have been discussed in detail (Ioannou et al., 2016).

Supernumerary teeth have been associated with various syndromes and disorders including Down's and Gardner's, cleidocranial dysostosis, and cleft lip and palate (Kumar and Gopal, 2013; Menezes and Vieira, 2008; Millhon and Stafne, 1941; Panjwani et al., 2011; Sandler, 1951); however, they have not been described in detail in cases of congenital syphilis. Supernumerary teeth are observed when more than 20 deciduous or 32 permanent teeth are present in an individual. They can erupt, remain unerupted, or become impacted (Kara et al., 2012; Mali et al., 2012). Their appearance can be unilateral, bilateral, as a single tooth or in multiples (Brinkmann et al., 2012; Cavalcanti et al., 2011; Harris and Clark, 2008). The morphology of supernumerary teeth can vary in each individual from normal in shape and size, normal shape and reduced in size, conical in shape and abnormal in shape and reduced in size (Harris and Clark, 2008; Kumar and Gopal, 2013; Rahnama et al., 2014).

This paper presents a case of congenital syphilis in an African American woman dating from the early 20th century with a fourth mandibular molar. A focus will be made on the development of the fourth molar in the presence of a disease, which primarily affects dental development.

\section{MATERIALS AND METHODS}

During a systematic examination of 28 skeletons held at the Smithsonian museum in Washington, DC, whose documentation stated that they had "treponemal or treponemal congenital" disease, a case of a supernumerary mandibular distomolar in one individual (P000707) was revealed. This individual was an African American female, who was born in 1903 and died of pulmonary tuberculosis in 1929, at 26 years of age. Occlusal and oblique X-rays of the mandible were taken using a Frankenstein unit to see whether a fourth molar was present on the right side. Chemical analysis was performed to detect any levels of mercury. A Bruker Tracer III-V handheld analyser was used on hypoplastic portions of the central and lateral incisors. The initial analysis used an allelements setting. The settings for the following test were elevated to $(0.001$ " $\mathrm{Cu}, 0.001$ " Ti, 0.012 " $\mathrm{Al}$ filter at $40 \mathrm{keV} / 16$ micro amps for 300 seconds, without vacuum) (Ioannou et al., In press).

\section{All maxillary permanent teeth were present, the} central and lateral incisors, canines, premolars and all three molars. The enamel of the central incisors from the incisal third to the middle third of the crown appears mottled and thin (Figure 1). The incisal third of the lateral incisors and left canine demonstrate the same mottled appearance and pitted enamel hypoplasia. Deep pits are apparent toward the middle third of the crown of the central incisors and incisal third of the lateral incisors and canines. In addition to signs caused by mercury on the incisors and canines, other teeth display isolated hypoplastic pits. Maxillary premolars are not affected. First permanent molars have abnormal occlusal surfaces, with cusps reduced in size and pitting hypoplasia, which is also consistent with the side effects of mercury (Figure 2). Diseased enamel is clearly demarcated from the healthy enamel on the cervical third of the crown. The morphology of the second and third permanent maxillary molars is normal with normal groove patterns, but there is some enamel pitting on the occlusal surface.

Mandibular permanent teeth include the central and lateral incisors, left and right canines, first and second premolars, second and third molars and the

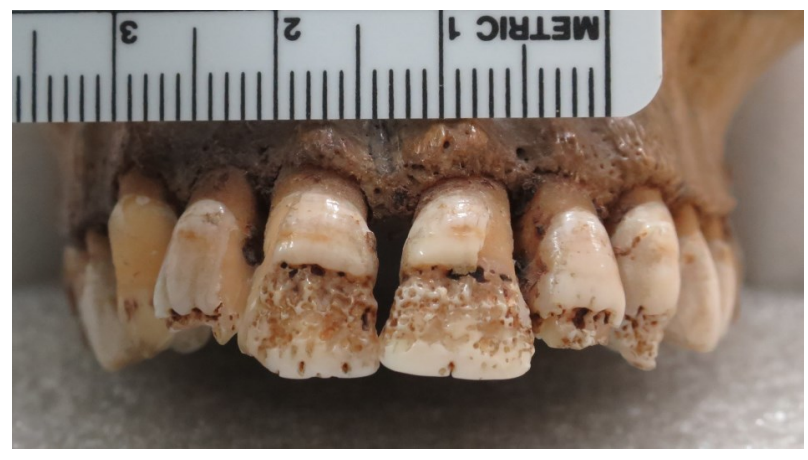

Figure 1. The maxillary central and lateral incisors and left canine display hypoplastic enamel seen in patients with congenital syphilis treated with mercury. Signs include thin enamel, pitted enamel hypoplasia (in some places very deep), and distinct demarcation separating diseased from healthy enamel. 


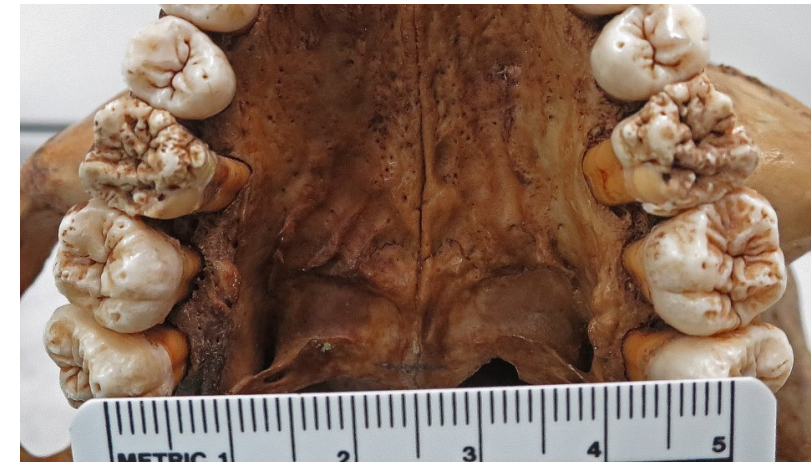

Figure 2. Occlusal view of the maxilla. First permanent molars have abnormal surfaces with small cusps and pitting hypoplasia

distomolar. The first permanent molars were lost ante-mortem, possibly by extraction and their alveoli are completely healed. All mandibular incisors have mottled enamel (Figure 3). The left and right second molars and the third left molar do not display severe hypoplasia, save for minor pitting. Their occlusal surfaces are crenulated. The third permanent molar on the right side is represented by its roots only. The crown has broken off probably after its destruction by dental caries. On the left side, in the mandible, there is a fully erupted fourth molar (distomolar). Its crown has normal molar morphology, but is smaller in size in comparison to the other permanent molars present. The arrangement of groves resembles the +4 pattern. However, the groove pattern is complex because of crenulation. Entoconid, metaconid, hypoconid and protoconid are present, and it appears that there may be a narrow metaconulid, but crenulations make it difficult to determine (Figure 4). An oblique X-ray of the mandible shows that the distomolar only has one root with a large pulp chamber extending far down towards its apex, suggesting a taurodont condition (Figure 5). The third molar on the left is large and crowded between the distomolar and adjacent second molar. Its crown is rotated approximately 10 degrees and tilted mesially. Inspection of the X-ray

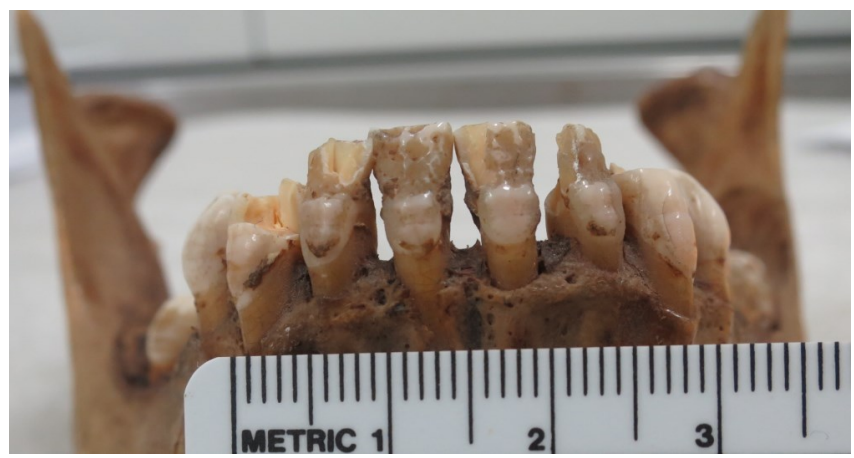

Figure 3. The anterior view of the mandibular incisors displaying enamel defects does not reveal the presence of the antimeric distomolar (Figure 6). All molar crowns appear crenulated.

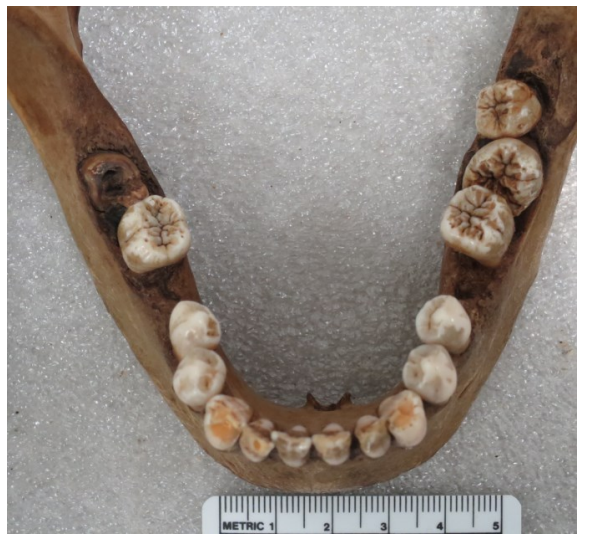

Figure 4. Occlusal surface of the mandible. The first permanent molars were lost ante-mortem. Both second molars, the left third molar and left fourth molar are present. The right third molar is represented by its root only. The fourth molar displays normal molar morphology

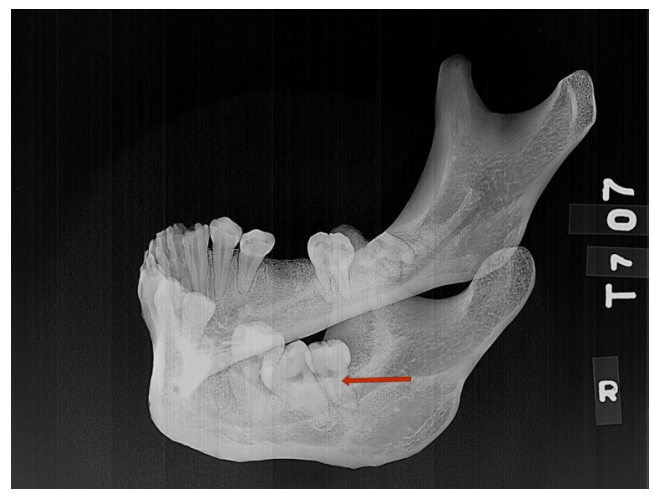

Figure 5. Oblique $X$-ray image of the mandible shows that the distomolar has only one root and that there is no antimeric distomolar. Note the large extent of the pulp cavity in the distomolar, suggesting it is a taurodont molar.

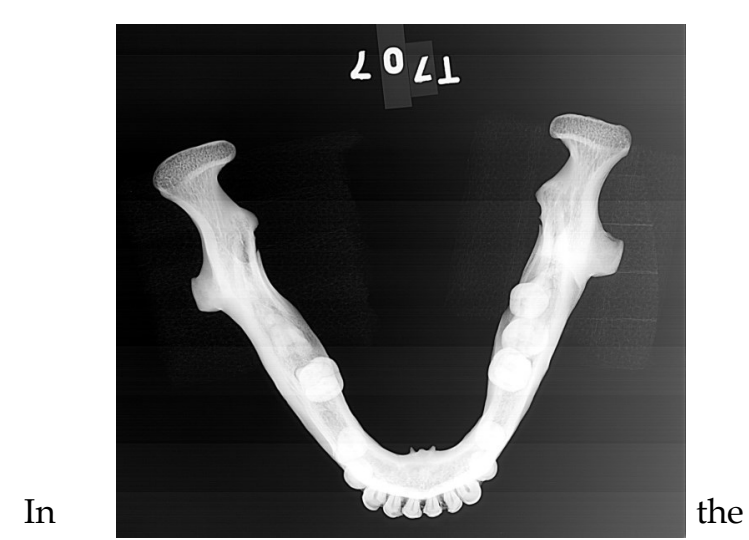

Figure 6. X-ray of the occlusal view of the mandible does not show any evidence of a right fourth molar 
post cranial skeleton, limited areas of nodular periosteal reaction were observed on the long bones including the right tibia, fibula, humeri, radius, ulnae, and femora, as well as the lateral surface of the left ilium. The left femur had lytic destruction along the lateral border of the head in the anterior aspect, "classic" striated periosteal reaction is not noticeable.

\section{DISCUSSION}

Here we present a case of congenital syphilis with a supernumerary distomolar in an African American woman. Although this condition is very rare during this time, it is probable, as one other case has been documented (Jacobi et al., 1992). However, in this case, the dental abnormalities in P000707 indicate that she was treated with mercury soon after birth. Changes in the morphology of the central maxillary incisors and left canine have enamel malformations that are compatible with dental abnormalities observed by Hutchinson in patients with congenital syphilis administered treatment containing mercury (Figure 7). Crown formation of the central permanent incisors begins at approximately three to four months postnatally and is complete at approximately 4 to 5 years of age (Nelson and Ash Jr, 2010). The specific changes in enamel caused by mercury are seen in one third of the crown, therefore, treatment would have started in the middle of the first year of life and

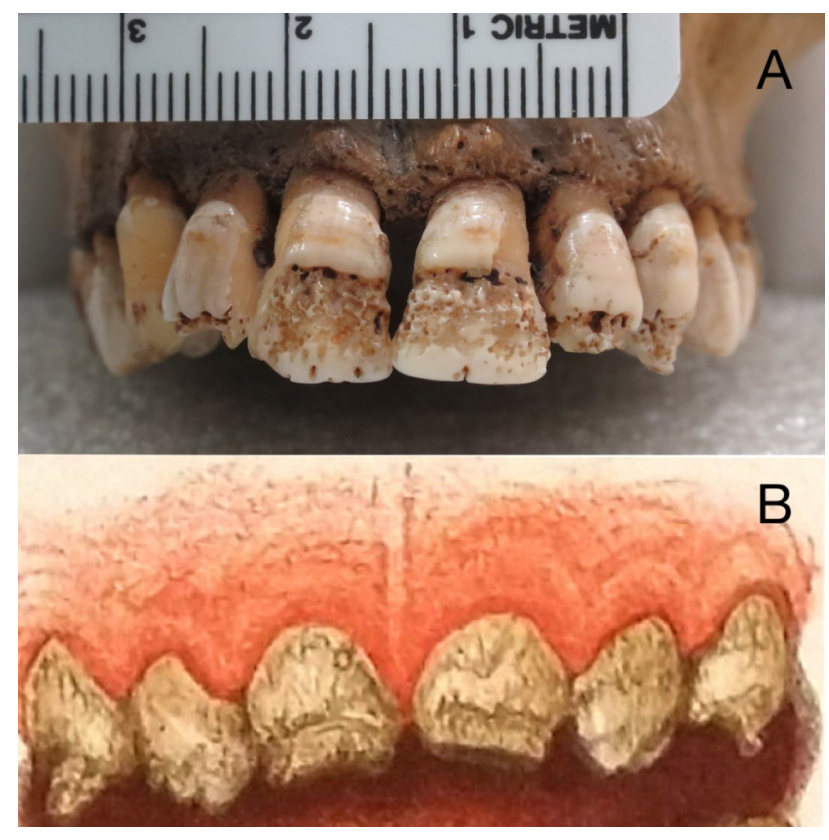

Figure 7. (A) Anterior teeth of P000707 (B) Patient treated with mercury as presented by Hutchinson in 1878 (16 year old boy). Both (A) and (B) display similarities in enamel abnormalities that occur as a result of treatments containing mercury. Mercury would have been administered at a somewhat older age in P000707 than in Hutchinson's patient. Hutchinson, (1878) p. 53, Plate VI, Items I (A) ceased at approximately 2 years of age. Similarly, severe enamel malformations are observed on the lateral incisors and canines that start forming later than the central incisors.

The morphology of the maxillary first permanent molars demonstrates a normal groove pattern towards the mesial end of the crown, while the rest of crowns' occlusal surfaces are reduced in size and hypoplastic. As the incisal third of the central incisors and a portion of the occlusal surface of the first permanent molars appears to be normal, the rest of the crown is affected, which may be an indication that the onset of the infection was late in relation to tooth development.

Congenital syphilis is known to produce specific dental abnormalities characteristic of the disease. However, it has been noted that in some cases of congenital syphilis, the classic dental changes that are usually observed such as Hutchinson incisors, Moon's molar and Fournier's molars do not occur (Švejda, 1952). Hutchinson also observed and described certain dental abnormalities that occurred as an effect of treatments containing mercury (Hutchinson, 1878). The dental abnormalities produced by the disease itself and treatments containing mercury were so distinct that Hutchinson deemed it worthy to document and illustrate both as separate entities. It is worth noting that the crescentic notch that occurs in the maxillary central incisors of congenital syphilis patients is not observable if they were treated with mercury (Hutchinson, 1878). The features observed in this P000707 are typical signs of teeth treated with mercury in patients with congenital syphilis (Hutchinson, 1878; Ioannou et al., 2016).

While the results of the chemical analysis detected no levels of mercury, this neither confirms nor disproves that mercury was administered to this individual. Various explanations could be considered. It is possible that the low levels of mercury in the enamel could not be detected by the equipment. Another possible explanation for the lack of mercury detected could be due to the quick turnover rate of mercury in the body. The half-life of mercury ranges from 58 days for elemental mercury, 1-2 months for mercuric mercury (e.g. $\mathrm{HgCl}_{2}$ ), to $70-80$ days for methylmercury (National Research Council (US) 2000). Taking into account that this individual was treated with mercury for congenital syphilis in the early stages of life and died at 26 years of age, it is not abnormal to find extremely low levels of mercury. As indicated by Hutchinson, if $648 \mathrm{mg}$ (10 grains) of mercury were introduced in a body of a young individual, after 20 years only a minute quantity of mercury would remain $\left(2.13^{*} 10^{-25} \mathrm{mg}\right)$. Thus, it is more likely that a majority of the mercury would be cleared out, making it undetectable. 
Other elements considered in the differential diagnosis include lead, zinc, copper and cadmium. High levels of lead can cause a decrease in microhardness of enamel (Gerlach et al, 2002) but cannot cause malformations of the enamel (Gerlach et al, 2002; Youravong et al, 2005). Fosse and Berg-Justesen (1977, 1978, 1978) and Tvinnereim et al. (1999) examined concentrations of zinc, copper, and cadmium in teeth and bone in humans and mice and recorded the difference in concentration of these elements between enamel, dentin, and bone, but did not record any changes or malformations in enamel development.

In relation to changes on the post cranial skeleton of P000707, since the individual died of tuberculosis, it is difficult to say which of those described pathological changes could be due to treponemal infection.

The crown morphology of the distomolar is normal, unaffected by the disease, nor by treatments containing mercury. The smaller size of the distomolar is unlikely to be caused by congenital syphilis. Clinical studies have shown that distomolars can demonstrate normal molar morphology, have as many as three to seven cusps and be reduced in size, in comparison to the other permanent molars (Asrani et al., 2006; Ceperuelo et al., 2015; Kumar and Gopal, 2013; Ohata et al., 2013; Shahzad and Roth, 2012). The normal crown morphology in this case may be due to the time at which the development of the fourth molar began. It is the early stage of the disease that affects dental development. It occurs soon after birth and becomes the tertiary stage after several weeks. Tertiary syphilis does not affect tooth development. The development of the third permanent molar begins at approximately 7 to 10 years of age and the tooth is fully erupted between the ages of 17 and early 20s (Liversidge, 2015). It is possible that the fourth distomolar could have developed at the same age or even later. If the fourth molar had developed soon after the third molar, P000707 would have been in the tertiary stage of the disease; therefore, the disease could be asymptomatic and would not have affected amelogenesis or odontogenesis of the supernumerary fourth molar. However, it is possible that the fourth molar developed sooner. Studies have shown that fourth molars can appear between the ages of 11 and 16 years (Delgado et al., 2014; Menardía-Pejuan et al., 2000; Orhana et al., 2006; Vlaykov et al., 2015).

It also appears common that distomolars demonstrate a single root, unlike the multiple roots observed in the other permanent molars (Ceperuelo et al., 2015; Ohata et al., 2013; Rahnama et al., 2014). However, root formation can vary among individuals (complete with closed apex or incomplete) (Ceperuelo et al., 2015; Kokten et al., 2003; Ohata et al., 2013). Since the distomolar in this case is taurodontic, it is not possible to determine whether it had fused multiple roots or a single root because no separate root canals can be seen. At least formally, the root is a single unit. The cause of taurodontism is unclear. It has been associated with various syndromes (Andersson et al., 2013; Keeler, 1973; Rajić and Mestrović, 1998) and multiple theories have been suggested in the literature (Alvesalo and Varrela, 1991; Witkop Jr et al., 1988). In this case, it should be considered that the proportions of the root to crown size and pulp cavity to root canal volumes may have developed abnormally in the supernumerary, thus not normal, tooth without any special causes.

The development of extra teeth is not fully understood, although multiple theories have been suggested such as hyperactivity within the dental lamina, and dichotomy of the tooth germ and these may be linked to genetic factors (Kokten et al., 2003; Kumar and Gopal, 2013). For instance, Martínez-González et al. (2012) found them in $0.96 \%$, Shahzad and Roth (2012) in $2.2 \%$ and Kara et al. (2012) in $0.33 \%$. It has been found that supernumerary molars were also more prevalent in African Americans (6.4\%), than in European Americans (0.9\%) (Shahzad and Roth, 2012). It has been suggested that African Americans exhibit extra teeth more often than European Americans (Harris and Clark, 2008), which may be related to African Americans having larger dental arches and greater crown and root dimensions. This would increase a probability of the appearance of the distomolar in an African American suffering from congenital syphilis.

\section{CONCLUSION}

A systemic infection such as congenital syphilis and its treatment with mercury may not influence the development of supernumerary teeth due to: (1) the age at which the development of the fourth molar takes place, (2) the stage of the infection at the time of development and (3) the age at which treatments containing mercury are administered to patients with congenital syphilis.

\section{ACKNOWLEDGMENTS}

The authors thank Dr. David Hunt for taking the Xray images and Rhonda Coolidge for measuring mercury levels at the Smithsonian Museum Support Centre in Washington, DC.

\section{LITERATURE CITED}

Alvesalo L, Varrela J. 1991. Taurodontism and the presence of an extra $\mathrm{Y}$ chromosome: study of 47 , XYY males and analytical review. Hum Biol 63:31-38.

Andersson E-M, Axelsson S, Gjolstad L-F, Storhaug K. 2013. Taurodontism: A minor diagnostic criterion in Laurence-Moon/Bardet-Biedl syndromes. Acta Odontol Scand 71:1671-1674. 
Asrani MK, Tarsariya VM, Pathan JM. 2006. Bilateral maxillary fourth and fifth molars: An unusual radiographic appearance. Indian J Dent Res 27:103-105.

Bernfeld WK. 1971. Hutchinson's teeth and early treatment of congenital syphilis. Brit J Vener Dis 47: 54-56.

Brinkmann JCs-Bn, Barona-Dorado C, MartínezRodriguez N, Martín-Ares M, MartínezGonzález JM. 2012. Nonsyndromic multiple hyperdontia in a series of 13 patients: Epidemiologic and clinical considerations. J Am Dent Assoc 143:e16-24.

Cavalcanti AL, Barros de Alencar CR, Guedes de Carvalho Neto L. 2011. Bilateral maxillary and mandibular fourth molars: a case report and literature review. J Investig Clin Dent 2:296-299.

Ceperuelo D, Lozano M, Duran-Sindreu F, Mercadé M. 2015. Supernumerary fourth molar and dental pathologies in a Chalcolithic individual from the El Mirador Cave site (Sierra de Atapuerca, Burgos, Spain). HOMO 66:15-26.

Delgado FE, Youssef ADM, Jonasson T, Landucci A, Ulbrich LM, Rodrigues de Araujo M. 2014. Multiple fourth molars: surgical treatment in young patient. RSBO 11:405-410.

Fiumara NJ, Lessell S. 1970. Manifestations of late congenital syphilis: An analysis of 271 patients. Arch Dermatol 102:78-83.

Fosse G, Berg Justesen NP. 1977. Cadmium in deciduous teeth of Norwegian children. Int J Environ Stud 11:17-27.

Fosse G, Berg Justesen NP. 1978. Zinc and copper in bone and teeth of mice. Int J Environ Stud 12:111 -120 .

Fosse G, Berg Justesen NP. 1978. Zinc and copper in deciduous teeth of Norwegian children. Int J Environ Stud 13:19-34.

Fournier A. 1886. La syphilis héréditaire tardive Paris: G. Masson. p. 68-124.

Gerlach RF, Cury JA, Krug FJ, Line SRP. 2002. Effect Mali S, Karjodkar FR, Sontakke S, Sansare K. 2012. of lead on dental enamel formation. Toxicology 175:27-34.

Harris EF, Clark LL. 2008. An Epidemiological study of hyperdontia in American blacks and whites. Angle Orthod 78:460-465.

Hira SK, Bhat GJ, Patel JB, Din SN, Attili RV, Patel MI, Baskarnathan S, Hira RS, Andu NN. 1985. Early congenital syphilis: Clinico-radiologic features in 202 patients. Sex Transm Dis 12:177-183.

Hutchinson J. 1863. A clinical memoir on certain diseases of the eye and ear, consequent on inherited syphilis: with an appened chapter of commentaries to offspring, and its more remote consequences. London: John Churchill. p. 203-206 syphilis. Lancet 103:157-159.

Hutchinson J. 1878. Illustrations of clinical surgery consisting of plates, photographs, woodcuts, diagrams etc. Illustrating surgical diseases, symptoms and accidents, also operative and other methods of treatment, with descriptive letterpress. London: J. \& A. Churchill. p. 53-57.

Ioannou S, Hunt D, Coolidge R, Hennegerg M. In press. Dental characteristics of early 20th century cases of congenital syphilis. Am J Phys Anthrop.

Ioannou S, Sassani S, Henneberg M, Henneberg RJ. 2016. Diagnosing congenital syphilis using Hutchinson's method: Differentiating between syphilitic, mercurial, and syphilitic-mercurial dental defects. Am J Phys Anthropol 159:617629.

Jacobi KP, Cook DC, Corruccini RS, Handler JS. 1992. Congenital syphilis in the past: Slaves at Newton Plantation, Barbados, West lndies. Am J Phys Anthropol 89:145-158.

Kara M-Is, Aktan A-M, Ay S, Bereket C, Şener Is, Bülbül M, Ezirganlı Se, Polat H-B. 2012. Characteristics of 351 supernumerary molar teeth in Turkish population. Med Oral Patol Oral Cir Bucal 17:e395-400.

Karnosh LJ. 1926. Histopathology of syphilitic hypoplasia of the teeth. Arch Derm Syphilol 13:25-42.

Keeler C. 1973. Taurodont molars and shovel incisors in Klinefelter's syndrome. J Hered 64:234-236.

Kokten G, Balcioglu H, Buyukertan M. 2003. Supernumerary fourth and fifth molars: a report of two cases. J Contemp Dent Pract 4:67-76.

Kumar DK, Gopal KS. 2013. An epidemiological study on supernumerary teeth: a survey on 5,000 people. J Clin Diagn Res 7:1504-1507.

Liversidge HM. 2015. Tooth eruption and timing. In: Scott JD, editor. A Companion to Dental Anthropology, 1st ed. New York: Wiley \& Sons. $p$ 159-171.

Supernumerary teeth in non-syndromic patients. Imaging Sci Dent 42:41-45.

Martínez-González JM, Cortés-Bretón Brinkmann J, Calvo-Guirado JL, Arias Irimia O, BaronaDorado C. 2012. Clinical epidemiological analysis of 173 supernumerary molars. Acta Odontol Scand, 70:398-404.

McLean S. 1931. II. The correlation of the roentgenographic and pathologic aspect of congenital osseous syphilis. Am J Dis Child 41:363-395.

Menardía-Pejuan V, Berini-Aytes L, Gay-Escoda C. 2000. Supernumerary molars: A review of 53 cases. Bull Group Int Rech Sci Stomatol Odontol 42:101-105.

Hutchinson J. 1874. When and how to use mercury in Menezes R, Vieira AR. 2008. Dental anomalies as Part 
of the cleft spectrum. Cleft Palate Craniofac J 45:414-419.

Millhon JA, Stafne EC. 1941. Incidence of supernumerary and congenitally missing lateral incisor teeth in eighty-one cases of harelip and cleft palate. Am J Orthod Oral Surg 27.

Moon H. 1884. Dental surgery. In: Bryant T, editor. A manual for the practice of surgery. London: J \& A Churchill. p 637-674.

Nelson SJ, Ash Jr MM. 2010. Wheeler's Dental Anatomy, Physiology and Occlusion, 9th ed ed. St Louis: Saunders Elsevier. p. 31

Ohata H, Hayashi K, Iwamoto M, Muramatsu K, Watanabe A, Narita M, Suga K, Takano N, Shibahara T. 2013. Three Cases of Distomolars. Bull Tokyo Dent Coll 54:259-264

Orhana AI, Özer L, Orhan K. 2006. Familial occurrence of nonsyndromal multiple supernumerary teeth: a rare condition. Angle Orthod 76:891-897.

Panjwani S, Bagewadi A, Keluskar V, Arora S. 2011. Gardner's Syndrome. J Clin Imaging Sci 1:1-4.

Putkonen T, Paatero YV. 1961. X-ray photography of unerupted permanent teeth in congenital syphilis. Brit J Vener Dis 37: 190-196.

Rahnama M, Szyszkowska A, Pulawska M, SzczerbaGwozdz J. 2014. A rare case of retained fourth molar teeth in maxilla and mandible. Case report Curr Issues Pharm Med Sci 27:118-120.

Rajić Z, Mestrović SR. 1998. Taurodontism in Down's syndrome. Coll Antropol. 22: 63-67.

Rasool MN, Giovender S. 1989. The skeletal manifestations of congenital syphilis. A review of 197 cases. Bone Joint J 71-B:752-755.

Sandler HC. 1951. Cleidocranial dysostosis in four siblings. Am J Orthod 37:584-593.

Shahzad KM, Roth LE. 2012. Prevalence and management of fourth molars: a retrospective study and literature review. J Oral Maxillofac Surg 70:272275.

Švejda J. 1952. Zmeny na zubech pri kongenitalni syfilis. Cesk Stomatol 52:321-341.

Tvinnereim HM, Eide R, Riise T, Fosse G, Wesenberg GR. 1999. Zinc in primary teeth from children in Norway. Sci Total Environ 226:201-212

Vlaykov A, Sharlanov D, Vicheva D. 2015. Fourth mandibular molar in a pediatric patient - case report. Rom J Rhinolo 5:229-231.

Warner F. 1881. East London hospital for children: Cases of congenital syphilis Lancet 117:173-174.

Witkop Jr CJ, Keenan KM, Červenka J, Jaspers MT. 1988. Taurodontism: An anomaly of teeth reflecting disruptive developmental homeostasis. Am J Med Genet 31:85-97.

Youravong N, Chongsuvivatwong V, Teanpaisan R, Geater AF, Dietz W, Dahlén, G, Norén, JG.2005. Morphology of enamel in primary teeth from children in Thailand exposed to environmental lead. Sci Total Environ 348: 73-81. 